\title{
Seletividade e eficiência de herbicidas no controle de plantas daninhas na cultura do feijão-caupi
}

\author{
Mauricio Antonio Cuzato Mancuso ${ }^{1 *}$,Bruno Corrêa Aires ${ }^{l}$, Eduardo Negrisoli ${ }^{2}$, Marcelo Rocha Corrêa $^{2}$, \\ Rogério Peres Soratto ${ }^{1}$
}

$10.1590 / 0034-737 X 201663010004$

\section{RESUMO}

A falta de conhecimento sobre herbicidas para o manejo químico das plantas daninhas é uma das principais limitações para a expansão da cultura do feijão-caupi, na região centro-sul do Brasil. Com o objetivo de avaliar a seletividade e a eficiência de herbicidas na cultura do feijão-caupi, foram conduzidos dois experimentos de campo, um com a cultivar BRS Guariba e, outro, com BRS Novaera, em Botucatu-SP. Em ambos os experimentos, o delineamento utilizado foi o de blocos casualizados, em esquema fatorial 3 × $2+2$, com quatro repetições. Os tratamentos foram constituídos pelas combinações de três herbicidas (bentazona, fomesafem e diclosulam) com duas épocas de aplicação (inicial e tardio), além de uma testemunha capinada e, outra, sem capina. O herbicida diclosulam provocou elevada fitotoxicidade e reduziu a população de plantas, enquanto o bentazona proporcionou os menores níveis de fitointoxicação às duas cultivares de feijão-caupi. O fomesafem, especialmente quando aplicado na fase inicial, foi o mais eficaz no controle das plantas daninhas e, mesmo causando fitotoxicidade à cultura do feijão-caupi, propiciou população de plantas adequada, bem como produtividades de grãos semelhantes às obtidas com a testemunha capinada. Assim, conclui-se que o herbicida fomesafem é o mais eficiente para ambas as cultivares de feijão-caupi.

Palavras-chave: Vigna unguiculata, Controle de plantas daninhas, Fitoxicidade.

\section{ABSTRACT}

\section{Selectivity and efficiency of herbicides in controlling weeds on cowpea crop}

A lack of knowledge about herbicides for chemical weed control is one of the major difficulties for the expansion of the cowpea crop in the mid-south region of Brazil. Aiming to evaluate the selectivity and efficiency of herbicides for cowpea crop, two field experiments, one of them with BRS Guariba and the other with BRS Novaera, were carried out in Botucatu, São Paulo, Brazil. In both experiments, the experimental design was a randomized block, in a $3 \times 2+2$ factorial scheme, with four replications. The treatments were a combination of three herbicides (bentazon, fomesafen, and diclosulam) and two application times (early and late), besides a weeded control and a non-weeded control. The herbicide diclosulan provided high phytotoxicity and reduced plant population, while bentazon provided the lowest levels of phytointoxication in both cowpea cultivars. The fomesafen, especially when applied in the initial phase, was the most effective in controlling weeds and even causing phytotoxicity to cowpea crop, provided adequate population of plants and grain yield similar to those obtained in the weeded control. Thus, it is concluded that the herbicide fomesafen is the most efficient to both cowpea cultivars.

Key words: Vigna unguiculata, Weed control, Phytotoxicity.

\footnotetext{
Submetido em 04/08/2014 e aprovado em 22/08/2015.

' UNESP, Faculdade de Ciências Agronômicas, Botucatu, São Paulo, Brasil. macmancuso@hotmail.com; braires1@hotmail.com; soratto@fca.unesp.br

${ }^{2}$ Techfield Assessoria e Consultoria Agrícola e Ambiental. eduardo.negrisoli@gmail.com; marcelorcorrea@uol.com.br
} 


\section{INTRODUÇÃO}

O feijão-caupi [Vigna unguiculata (L.) Walp.] apresenta grande importância socioeconômica para as regiões norte e nordeste do Brasil, onde é amplamente cultivado, em virtude, essencialmente, da sua adaptação às condições edafoclimáticas (Xavier et al., 2006). Contudo, por apresentar ciclo relativamente curto, entre 60 e 80 dias, e desenvolver-se bem em condições de pouca disponibilidade hídrica e baixa fertilidade do solo (Embrapa, 2002), seu cultivo tem-se expandido em larga escala na região centro-oeste, sendo conduzido, especialmente, após a cultura da soja, como segunda safra ou safrinha (Castelletti \& Costa, 2013).

A cultura apresenta produtividade média de 300 a 400 $\mathrm{kg} \mathrm{ha}^{-1}$, considerada baixa, em virtude da utilização de tecnologias pouco avançadas. Desta forma, há necessidade de se adotarem práticas que viabilizem incrementos de produtividade, de maneira ecológica e economicamente sustentável (Soares et al., 2006).

Dentre os maiores problemas para a produção de feijão-caupi, estão as plantas daninhas. Em virtude de apresentar ciclo curto, o feijão-caupi torna-se extremamente susceptível à competição com plantas daninhas, especialmente no início do desenvolvimento (Lamego et al., 2011), podendo ter perdas de produtividade de 13 a $60 \%$ (Li et al., 2004). Muhammad et al. (2003) relataram que a presença de plantas daninhas na cultura do feijão-caupi reduziu a produtividade de grãos em $82 \%$, sendo observado que não foi alterada a produtividade quando se controlaram as plantas daninhas até 45 dias após a semeadura. Em outro trabalho, Oliveira et al. (2010) concluíram que as produtividades de três cultivares de feijão-caupi foram reduzidas em praticamente $90 \%$, por causa da existência de plantas daninhas durante todo o ciclo. Ainda, plantas daninhas na lavoura podem prejudicar a operação de colheita, além de servirem como hospedeiras para pragas e doenças (Lamego et al., 2011).

A capina tradicional é uma operação cada vez mais onerosa, em virtude do aumento constante dos salários e da pouca disponibilidade da mão de obra, principalmente no momento de maior demanda. Assim, essas limitações têm gerado a necessidade de adotar medidas de controle alternativas, no cultivo em larga escala de feijão-caupi (Ishaya et al., 2008). Nesse contexto, destaca-se o controle químico de plantas daninhas por herbicidas, manejo que poderia proporcionar maior eficiência ao sistema produtivo da cultura.

Nos últimos anos, a Embrapa Meio-Norte lançou diversas cultivares de feijão-caupi, de porte ereto ou semiereto, como BRS Guariba e BRS Novaera (Freire Filho et al., 2008; Gonçalves et al., 2009), os quais apresentam elevado potencial produtivo e são adaptados à colheita mecanizada. Porém, essas cultivares têm sido lançados sem um pacote tecnológico adequado para a boa expressão de suas características superiores, o que tem limitado significativamente o seu cultivo (Embrapa, 2002). Dentre esses fatores de produção, está o controle de plantas daninhas de folhas largas, dificultado pela pouca disponibilidade de informações sobre herbicidas seletivos. Ainda não existe um herbicida seletivo registrado no Ministério da Agricultura, Pecuária e Abastecimento (MAPA) que possa ser utilizado, para o controle de plantas daninhas de folhas largas, na cultura do feijão-caupi no Brasil (Brasil, 2014). Dessa forma, é de suma importância a pesquisa de herbicidas que possam ser utilizados de forma segura na cultura do feijão-caupi, com o propósito de garantir produtividade satisfatória, com menor custo possível para o produtor. Herbicidas disponíveis no mercado, especialmente aqueles utilizados na cultura do feijãocomum (Phaseolus vulgaris L.), podem ser eficazes para o controle de plantas daninhas na cultura do feijão-caupi, sem causar alguma injúria; porém existe pouca informação disponível sobre o assunto.

Diante do exposto, o objetivo com este trabalho foi avaliar a seletividade dos herbicidas bentazona, fomesafem e diclosulam à cultura do feijão-caupi, aplicados em duas épocas de desenvolvimento das plantas daninhas e da cultura.

\section{MATERIAL E MÉTODOS}

Foram conduzidos dois experimentos, um com a cultivar BRS Guariba e, outro, com a cultivar BRS Novaera. Os experimentos foram conduzidos em Botucatu-SP (22 $2^{\circ} 8^{\prime}$ $\mathrm{S}, 4^{\circ} 23^{\prime} \mathrm{W}$ e $765 \mathrm{~m}$ de altitude). O solo do local é classificado como Latossolo Vermelho distroférrico (Embrapa, 2006). De acordo com Köppen, a classificação climática da região é Cwa, caracterizada pelo clima tropical de altitude, com inverno seco e verão chuvoso. As precipitações pluviais mensais e as temperaturas médias mensais, obtidas durante a condução do experimento, são apresentadas na Figura 1.

Antes da instalação dos experimentos, foram coletadas amostras de solo, na profundidade de 0-0,20 m e submetidas a análises químicas (Raij et al., 2001), registrando-se os resultados a seguir: $\mathrm{pH}\left(\mathrm{CaCl}_{2}\right)=4,9 ; \mathrm{P}_{\text {resina }}=23 \mathrm{mg} \mathrm{dm}^{-}$ 3; $\mathrm{K}, \mathrm{Ca}$ e $\mathrm{Mg}=1,8 ; 24 \mathrm{e} 10 \mathrm{mmol}_{\mathrm{c}} \mathrm{dm}^{-3}$, respectivamente; $\mathrm{H}$ $+\mathrm{Al}=44 \mathrm{mmol}_{\mathrm{c}} \mathrm{dm}^{-3} ;$ M.O. $=24 \mathrm{~g} \mathrm{dm}^{-3} ; \mathrm{CTC}=79,8 \mathrm{mmol}_{\mathrm{c}}$ $\mathrm{dm}^{-3}$ e V\% $=45$.

Em ambos os experimentos, o delineamento utilizado foi em blocos casualizados, em esquema fatorial $3 \times 2+2$, com quatro repetições. Os tratamentos foram constituídos pelas combinações de três herbicidas (bentazona, fomesafem e diclosulam) com duas épocas de aplicação (quando a maioria das plantas daninhas apresentava de 
quatro a seis pares de folhas definitivas e as plântulas de feijão-caupi apresentavam o primeiro par de folhas, denominado inicial, e no estádio de desenvolvimento mais avançado, quando as plantas daninhas apresentavam de oito a dez pares de folhas definitivas e as de feijão-caupi apresentavam três folhas verdadeiras, denominado tardio, além de duas testemunhas (sem aplicação de herbicidas), sendo uma capinada ( $100 \%$ de controle das plantas daninhas) e, outra, não capinada ( $0 \%$ de controle das plantas daninhas). Cada parcela foi constituída por quatro fileiras de plantas, com $6 \mathrm{~m}$ de comprimento, espaçadas entre si por $0,45 \mathrm{~m}$. As duas linhas centrais das parcelas foram consideradas como área útil experimental.

O experimento foi instalado em área sob sistema plantio direto, anteriormente cultivada com soja, na safra de verão 2010/2011. No dia 05/12/2011, foi realizado um levantamento de plantas daninhas, com a finalidade de caracterizar a comunidade presente na área experimental, sendo as espécies de maior ocorrência identificadas botanicamente e quantificadas, entre elas: Euphorbia heterophylla L. (leiteiro), Bidens pilosa L. (picão preto), Commelina benghalensis L. (trapoeraba) e Oxalis corniculata L. (trevo). Nessa mesma data, as plantas daninhas presentes na área foram manejadas com herbicida glifosato (1560 g do i.a ha ${ }^{-1}$ ), com pulverizador costal, pressurizado com $\mathrm{CO}_{2}$, com calibração proporcional a um volume de calda de $200 \mathrm{~L} \mathrm{ha}^{-1}$. A barra de pulverização era constituída de duas pontas do tipo jato plano "Teejet" XR 11002 VS, espaçadas 0,5 m entre si.

A semeadura do feijão-caupi foi realizada, mecanicamente, no dia 15/12/2011, sendo semeadas dez sementes viáveis por metro. A adubação de semeadura constou da aplicação de $250 \mathrm{~kg} \mathrm{ha}^{-1}$ da fórmula $\mathrm{N}-\mathrm{P}_{2} \mathrm{O}_{5}-\mathrm{K}_{2} \mathrm{O}$ 08-28-16. A emergência ocorreu aos cinco dias após a semeadura
(DAS) e o desbaste foi realizado aos 15 DAS, deixando-se sete plantas por metro (140 mil plantas ha ${ }^{-1}$ ).

Aos 20 DAS, foi realizada a aplicação, de forma manual e ao lado das fileiras de plantas, de $50 \mathrm{~kg} \mathrm{ha}^{-1} \mathrm{de} \mathrm{N}$ em cobertura, utilizando-se ureia como fonte. Os demais tratos culturais e fitossanitários executados estavam de acordo com os recomendados para a cultura na região.

As aplicações dos herbicidas foram realizadas aos 7 DAS, quando a maioria das plantas daninhas apresentava de quatro a seis pares de folhas definitivas (estádio inicial), e aos 22 DAS, quando apresentavam de oito a dez pares de folhas definitivas (estádio tardio). Para a aplicação dos herbicidas, utilizou-se um pulverizador costal com reservatório de $2 \mathrm{~L}$, pressurizado com $\mathrm{CO}_{2}$, sendo a calibração do equipamento proporcional a um volume de calda de $200 \mathrm{~L} \mathrm{ha}^{-1}$. A barra de pulverização era constituída de duas pontas do tipo jato plano "Teejet" XR 11002 VS, espaçadas de $0,5 \mathrm{~m}$ entre si. As doses utilizadas dos herbicidas foram: $720 \mathrm{~g}$ i.a. ha ${ }^{-1}$ de bentazona $\left(\right.$ Basagran $\left.^{\circledR}\right)$, $250 \mathrm{~g}$ i.a. ha ${ }^{-1}$ de fomesafem $\left(\right.$ Flex $\left.^{\circledR}\right)$ e 21 g i.a. ha ${ }^{-1}$ de diclosulam $\left(\right.$ Spider $\left.^{\circledR}\right)$. Em todas as caldas de pulverização, para todos os herbicidas, acrescentou-se 0,5 v/v do adjuvante Assist ${ }^{\circledR}$ (óleo mineral).

As avaliações visuais de controle das plantas daninhas pelos herbicidas e de fitointoxicação foram realizadas aos 9, 30 e 45 dias após a aplicação dos tratamentos (DAA), com uso de escala de notas de 0 (zero) a 100 (cem), em que 0 corresponde a nenhuma injúria nas plantas e, 100, à morte de todas as plantas (SBCPD, 1995).

A colheita da cultivar BRS Guariba foi realizada em 27/ 03/2012 e, a da cultivar BRS Novaera, em 16/04/2012, quando foram determinados os componentes da produção (número de plantas por hectare, número de vagens por planta, número de grãos por vagem e massa de 100 grãos), em

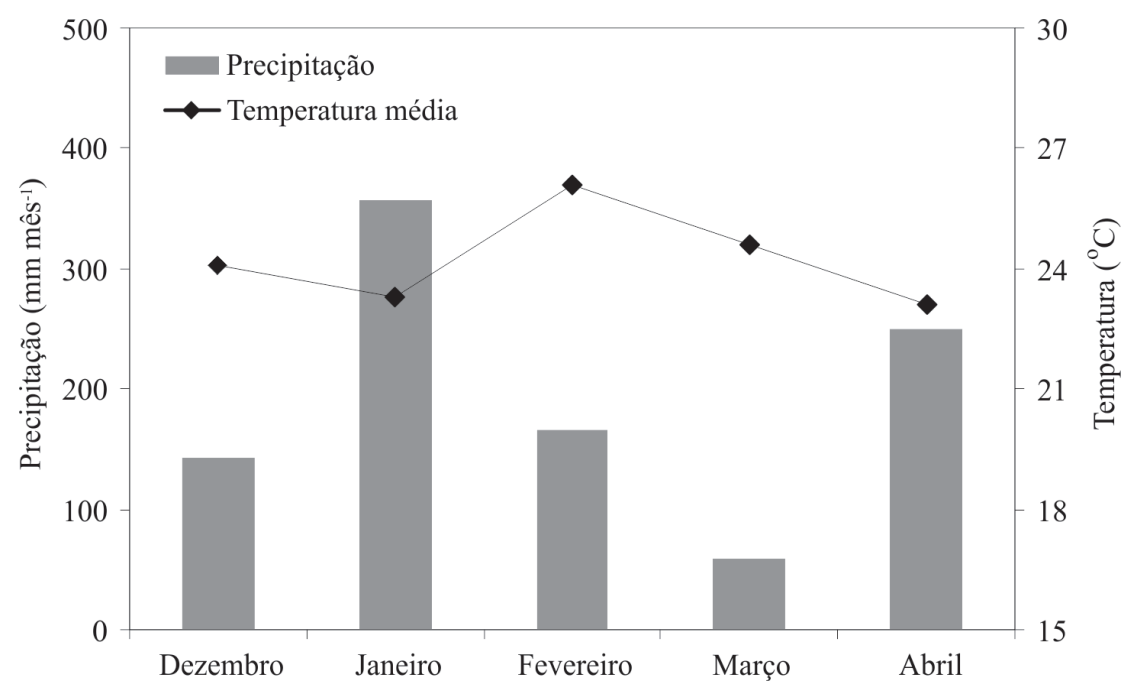

Figura 1: Precipitação pluvial e temperaturas médias mensais obtidas na área experimental, durante o período de dezembro de 2011 a abril de 2012. Botucatu, SP. 
dez plantas coletadas na área útil de cada parcela, e a produtividade de grãos (13\% de umidade, em base úmida), em duas fileiras de $4 \mathrm{~m}$ de comprimento.

Os resultados foram submetidos à análise de variância. As médias dos tratamentos componentes do fatorial foram comparadas entre si pelo teste $\mathrm{t}$ (LSD) a 5\% de probabilidade. Por meio do teste Dunnett, a 5\% de probabilidade, os contrastes ortogonais dos tratamentos do fatorial foram comparados com os das testemunhas. Para os resultados de percentagem de controle das plantas daninhas, combinaram-se as repetições de ambas as cultivares em apenas um teste, perfazendo um total de oito repetições para cada tratamento.

\section{RESULTADOS E DISCUSSÃO}

Na primeira época de avaliação (nove dias após a aplicação dos herbicidas - DAA), o fomesafem proporcionou, no geral, maior percentagem de controle de todas as plantas daninhas estudadas, especialmente quando aplicado de forma inicial (Tabela 1). Já aos 30 DAA, o diclosulam foi o herbicida que proporcionou maior percentagem de controle das plantas daninhas, principalmente quando aplicado tardiamente, seguido do fomesafem e bentazona. O diclosulam e o fomesafem foram os herbicidas que melhor controlaram as plantas daninhas da cultura do feijão-caupi aos 45 DAA. No geral, nessa época de avaliação, a aplicação inicial ou tardia dos herbicidas influenciou de forma similar o controle plantas daninhas.

No entanto, todos os herbicidas, bem como as épocas de aplicação avaliadas, foram pouco eficientes no controle de trevo e trapoeraba, resultando em percentagens inferiores a $50 \%$ (Tabela 1). Em alguns casos, inclusive, as plantas daninhas conseguiram recuperar-se entre as épocas de avaliação, como a trapoeraba, que na aplicação dos herbicidas na fase inicial apresentou percentagem de controle reduzida em épocas de avaliação mais tardias, o que leva a acreditar que as gemas apicais das plantas não foram comprometidas, ou, mesmo, que havia sementes na área que ainda estavam por germinar. Por outro lado, a percentagem de controle de leiteiro e, principalmente, de picão-preto, estava dentro de uma faixa maior que a das demais plantas daninhas, variando, em geral, de 54 a $98 \%$. Na maioria dos casos, a percentagem de controle aumentou em função da época de avaliação, sendo maior aos 45 DAA, provavelmente em virtude de algum efeito residual dos herbicidas utilizados ou, ainda, pelo fechamento da cultura (Tabela 1). Deve-se salientar que a cultura do feijão-caupi, assim como a do feijão-comum, apresenta ciclo relativamente curto, tornando-se extremamente susceptível à competição com plantas daninhas, especialmente na fase inicial de desenvolvimento (Lamego et al., 2011). Os mesmos autores comentam que o período em que as plantas daninhas causam maiores danos ao feijão-comum compreende os primeiros 30 dias da cultura e, portanto, é de suma importância que sejam controladas o quanto antes e de forma eficaz, por meio de um manejo adequado. Alguns trabalhos mostraram controle das plantas daninhas na cultura do feijão-caupi semelhantes aos resultados obtidos neste trabalho quando se utilizou a mistura metolachlor + prometryn em pré-emergência (Ishaya et al., 2008), oxadiazon em pré-emergência na cultivar BRS Guariba (Fontes et al., 2010) e imazaquin e pendimethalin, em duas variedades nigerianas (Chikoye et al., 2014), levando a crer que os herbicidas utilizados neste trabalho foram eficientes em controlar as plantas daninhas.

Contudo, os herbicidas fomesafem e diclosulam, sobretudo quando aplicados na fase inicial, promoveram maior fitointoxicação aos 9 DAA, nos duas cultivares de feijão-caupi (Tabela 2). Mesmo com os danos causados pela aplicação fomesafem, obteve-se população de plantas adequada (Tabela 3), estando de acordo com as recomendações da Embrapa (2002). Sabe-se que o fomesafem é um desregulador de membrana plasmática e, assim, seu contato com as plantas causa rapidamente necrose de tecidos. As injúrias ocorrem no momento em que é realizada a dessecação e se tornam visíveis de um a dois dias após a aplicação do herbicida (Lee et al., 1993). Burgos et al. (2007) observaram que a necrose foliar, em 42 linhagens e oito cultivares comerciais americanos de feijãocaupi, duas semanas após a aplicação de fomesafem, foi da ordem de 55 a $90 \%$, considerada extremamente severa. Procópio et al. (2009), trabalhando com feijão-comum, constataram que o maior nível de fitointoxicação às plantas ocorreu com a aplicação de fomesafen + chlorimuronethyl, variando de 53 a 77\%. Os mesmos autores comentam, ainda, que mesmo sendo o fomesafem um herbicida registrado para uso na cultura do feijão-comum, as cultivares apresentaram tolerância variável.

Já aos 30 DAA, o herbicida diclosulam foi o que causou mais injúrias, independentemente da época de aplicação, para a cultivar BRS Guariba, e de forma mais severa, com a aplicação tardia na cultivar BRS Novaera (Tabela 2). Nessa época de avaliação, o herbicida bentazona foi o que proporcionou menor fitointoxicação à cultivar BRS Guariba, além de não ter causado nenhum dano à cultivar BRS Novaera, tanto aplicado inicialmente quanto tardiamente. Aos 45 DAA, o diclosulam também foi o mais prejudicial ao feijão-caupi, porém de forma mais severa quando aplicado na fase inicial para a cultivar BRS Guariba e, na fase tardia, para a cultivar BRS Novaera. Novamente, a aplicação de bentazona, independentemente da época, praticamente não causou sintomas de fitointoxicação na cultivar BRS Novaera, aos 30 e aos 45 DAA. Sikkema et al. (2004) afirmam que os 
herbicidas chlorimuron-ethyl e cloransulam-methyl, aplicados em pós-emergência, não apresentam seletividade suficiente para serem registrados para uso na cultura do feijão-comum, visto que são do mesmo grupo químico (triazolopirimidina sulfonanilidas).
Em relação à população de plantas, constatou-se que os menores resultados, para ambas as cultivares, foram obtidos com a aplicação de diclosulam na fase inicial, proporcionando valores inferiores ao da testemunha capinada (TC) (Tabela 3). Esse fato ocorreu em virtude de o

Tabela 1: Valores médios de percentagem (\%) de controle das plantas daninhas avaliadas (trevo, trapoeraba, picão-preto e leiteiro), em função da aplicação de herbicidas nas fases inicial e tardia, na cultura do feijão-caupi

\begin{tabular}{|c|c|c|c|}
\hline \multirow{2}{*}{ Época de aplicação } & \multicolumn{3}{|c|}{ Herbicida } \\
\hline & Bentazona & Fomesafem & Diclosulam \\
\hline & & Trevo & \\
\hline & & 9DAA & \\
\hline Inicial & $17,5 \mathrm{Ba}^{(1)}$ & $44,1 \mathrm{Aa}$ & $23,7 \mathrm{Ba}$ \\
\hline \multirow[t]{2}{*}{ Tardia } & $11,9 \mathrm{ABa}$ & $6,4 \mathrm{Bb}$ & $16,0 \mathrm{Aa}$ \\
\hline & & 30 DAA & \\
\hline Inicial & $16,9 \mathrm{Ba}$ & $25,0 \mathrm{Aa}$ & $25,6 \mathrm{Aa}$ \\
\hline \multirow[t]{2}{*}{ Tardia } & $19,4 \mathrm{Ba}$ & $19,4 \mathrm{Ba}$ & $29,4 \mathrm{Aa}$ \\
\hline & & 45 DAA & \\
\hline Inicial & $15,6 \mathrm{Ba}$ & $26,9 \mathrm{Aa}$ & $29,4 \mathrm{Aa}$ \\
\hline \multirow[t]{3}{*}{ Tardia } & $18,7 \mathrm{Ba}$ & $21,9 \mathrm{Ba}$ & $31,9 \mathrm{Aa}$ \\
\hline & & Trapoeraba & \\
\hline & & 9DAA & \\
\hline Inicial & $32,5 \mathrm{Ba}$ & 41,9Aa & $28,7 \mathrm{Ba}$ \\
\hline \multirow[t]{2}{*}{ Tardia } & $14,4 \mathrm{Ab}$ & $15,0 \mathrm{Ab}$ & $20,0 \mathrm{Ab}$ \\
\hline & & 30 DAA & \\
\hline Inicial & $19,4 \mathrm{Aa}$ & $19,4 \mathrm{Aa}$ & $23,1 \mathrm{Ab}$ \\
\hline \multirow[t]{2}{*}{ Tardia } & $21,9 \mathrm{Ba}$ & $15,6 \mathrm{Ba}$ & $31,2 \mathrm{Aa}$ \\
\hline & & 45 DAA & \\
\hline Inicial & $21,9 \mathrm{Ba}$ & $21,9 \mathrm{Ba}$ & $30,6 \mathrm{Aa}$ \\
\hline \multirow[t]{3}{*}{ Tardia } & $22,5 \mathrm{Ba}$ & $16,9 \mathrm{Ba}$ & $33,1 \mathrm{Aa}$ \\
\hline & & Picão-preto & \\
\hline & & 9DAA & \\
\hline Inicial & $54,7 \mathrm{Bb}$ & $86,0 \mathrm{Aa}$ & $82,9 \mathrm{Aa}$ \\
\hline \multirow[t]{2}{*}{ Tardia } & $88,1 \mathrm{Aa}$ & $17,5 \mathrm{Bb}$ & $90,4 \mathrm{Aa}$ \\
\hline & & 30 DAA & \\
\hline Inicial & $98,1 \mathrm{Aa}$ & $85,0 \mathrm{Ba}$ & $96,0 \mathrm{ABa}$ \\
\hline \multirow[t]{2}{*}{ Tardia } & $93,1 \mathrm{Aa}$ & $73,7 \mathrm{Ba}$ & $97,5 \mathrm{Aa}$ \\
\hline & & 45 DAA & \\
\hline Inicial & $96,9 \mathrm{Aa}$ & $90,6 \mathrm{Aa}$ & $97,5 \mathrm{Aa}$ \\
\hline \multirow[t]{3}{*}{ Tardia } & $93,7 \mathrm{Aa}$ & $75,6 \mathrm{Bb}$ & $98,1 \mathrm{Aa}$ \\
\hline & & Leiteiro & \\
\hline & & 9DAA & \\
\hline Inicial & $7,5 \mathrm{Ca}$ & 49,4Aa & $25,6 \mathrm{Ba}$ \\
\hline \multirow[t]{2}{*}{ Tardia } & $12,5 \mathrm{Ba}$ & $19,4 \mathrm{ABb}$ & $30,0 \mathrm{Aa}$ \\
\hline & & 30 DAA & \\
\hline Inicial & $37,5 \mathrm{Ab}$ & $20,0 \mathrm{Bb}$ & $26,2 \mathrm{Bb}$ \\
\hline \multirow[t]{2}{*}{ Tardia } & $48,1 \mathrm{Ba}$ & $41,2 \mathrm{Ba}$ & $59,4 \mathrm{Aa}$ \\
\hline & & 45 DAA & \\
\hline Inicial & $43,1 \mathrm{ABb}$ & $35,0 \mathrm{Bb}$ & $44,4 \mathrm{Ab}$ \\
\hline Tardia & $58,1 \mathrm{Ba}$ & $46,9 \mathrm{Ca}$ & $69,4 \mathrm{Aa}$ \\
\hline
\end{tabular}

${ }^{(1)}$ Médias seguidas da mesma letra, minúscula na coluna (época de aplicação dos herbicidas) e maiúscula na linha (herbicidas), dentro de cada espécie de planta daninha e época de avaliação, não diferem entre si pelo teste $\mathrm{t}(p=0,05)$. Considerou-se que o cultivar não interferiu no controle das plantas daninhas e, portanto, combinaram-se as repetições de ambos os cultivares em apenas um teste, perfazendo um total de 8 repetições. Consideraram-se $100 \%$ de controle a testemunha capinada e $0 \%$ a testemunha sem capina. 
diclosulam ser recomendado apenas para a cultura da soja e, principalmente, por sua aplicação ser recomendada em pré-emergência. Além disso, quando aplicado em pósemergência, como neste experimento, pode acarretar redução da população de plantas, pelo uso inadequado do produto. Também para ambos as cultivares, a aplicação de fomesafem proporcionou população final de plantas superior à obtida com a testemunha não capinada (TNC), ou seja, o herbicida foi tão eficaz quanto a capina, o que proporcionou o crescimento das plantas de feijão-caupi livre de, ou com pouca competição com plantas daninhas. De fato, o fomesafem proporcionou, no geral, boa percentagem de controle (Tabela 1). Assim como o feijão-comum, o feijão-caupi apresenta um ciclo relativamente curto e, dessa forma, torna-se extremamente susceptível à competição com plantas daninhas, especialmente na fase inicial de seu desenvolvimento, como a emergência (Lamego et al., 2011). Além disso, a capacidade competitiva dos feijoeiros com as plantas daninhas é pequena, em virtude de eles apresentarem metabolismo fotossintético do tipo $\mathrm{C} 3$, respondendo, na produção de fotoassimilados, de forma inferior à das plantas $\mathrm{C} 4$, como o leiteiro (Kissmann \& Groth, 1992), sobretudo em condições de temperaturas mais elevadas e de alta intensidade luminosa (Procópio et al., 2009).

Para o número de grãos por vagem, tanto os herbicidas quanto a época de aplicação não tiveram influência nos resultados da cultivar BRS Guariba (Tabela 3). Já em relação à cultivar BRS Novaera, o maior número de grãos por vagem foi observado com a aplicação inicial de bentazona, superior ao de ambas as testemunhas. A bentazona, aplicada na fase inicial. controlou de forma mais eficientemente as plantas daninhas, especialmente trevo, picãopreto e leiteiro (Tabela 1), e proporcionou menor fitointoxicação da cultivar BRS Novaera (Tabela 2), o que favoreceu maior número de grãos por vagem de feijãocaupi (Tabela 3). O número de vagens por planta das cultivares não foi alterado pelos fatores analisados. Para massa de 100 grãos, o maior resultado obtido foi com a aplicação inicial de diclosulam no cultivar BRS Novaera, superando a TNC. Não se observou efeito dos tratamentos sobre a cultivar BRS Guariba. Corrêa \& Alves (2009) observaram que a aplicação de herbicidas para o controle de plantas daninhas na cultura da soja não proporcionou efeito significativo sobre os componentes da produção. Por outro lado, Usman (2013) concluiu que o uso de herbicidas de pré-emergência em feijão-caupi aumentou significativamente o número de vagens por planta e de grãos por vagem, provavelmente. por verificar-se, então, menor competição de plantas daninhas, em comparação com a da testemunha.

Em relação à produtividade de grãos, apesar de não se verificarem grandes diferenças, a aplicação inicial de bentazona proporcionou melhor resultado que o diclosulam, para a cultivar BRS Guariba (Tabela 3). Trezzi et al. (2010) constataram, na cultura do feijão-comum, que a aplicação dos herbicidas bentazona + imazamox proporcionou incremento de produtividade de aproximadamente $13 \%$, em comparação com a da testemunha não capinada. Já para a cultivar BRS Novaera, destaca-se o resultado obtido com a aplicação tardia de fomesafem, superior ao observado com a TNC (Tabela 3). Esse resultado está estreitamente ligado à percentagem de controle das plantas daninhas, pois o herbicida fomesafem apresentou maior efetividade (Tabela 1). Porém, Procópio et al. (2009) observaram que a aplicação de fomesafem reduziu significativamente a produtividade de grãos das cultivares de feijão-comum BRS Timbó e BRS Vereda, em 23 e 16\%, respectivamente, mesmo sendo

Tabela 2: Valores médios de percentagem (\%) de fitointoxicação nas cultivares de feijão-caupi BRS Guariba e BRS Novaera, em função da aplicação de herbicidas nas fases inicial e tardia

\begin{tabular}{|c|c|c|c|c|c|c|}
\hline \multirow{3}{*}{$\begin{array}{l}\text { Época de } \\
\text { aplicação }\end{array}$} & \multicolumn{3}{|c|}{ BRS Guariba } & \multicolumn{3}{|c|}{ BRS Novaera } \\
\hline & \multicolumn{3}{|c|}{ Herbicida } & \multicolumn{3}{|c|}{ Herbicida } \\
\hline & Bentazona & Fomesafem & Diclosulam & Bentazona & Fomesafem & Diclosulam \\
\hline & \multicolumn{6}{|c|}{ Fitointoxicação (\%) } \\
\hline & \multicolumn{6}{|c|}{9 DAA } \\
\hline Inicial & $25,7 \mathrm{Ca}^{(1)}$ & $67,5 \mathrm{Aa}$ & $57,5 \mathrm{Ba}$ & $17,5 \mathrm{Ca}$ & $60,0 \mathrm{Aa}$ & $50,0 \mathrm{Ba}$ \\
\hline \multirow[t]{2}{*}{ Tardio } & $7,5 \mathrm{Cb}$ & $17,0 \mathrm{Bb}$ & $38,7 \mathrm{Ab}$ & $\mathrm{OBb}$ & $2,2 \mathrm{Bb}$ & $9,5 \mathrm{Ab}$ \\
\hline & \multicolumn{6}{|c|}{30 DAA } \\
\hline Inicial & $8,7 \mathrm{Ca}$ & $21,2 \mathrm{Ba}$ & $26,2 \mathrm{Aa}$ & $0 \mathrm{Ca}$ & $6,2 \mathrm{Bb}$ & $9,5 \mathrm{Ab}$ \\
\hline \multirow[t]{2}{*}{ Tardio } & $2,7 \mathrm{Cb}$ & $10,2 \mathrm{Bb}$ & $23,2 \mathrm{Aa}$ & $0 \mathrm{Ca}$ & $10,7 \mathrm{Ba}$ & $22,5 \mathrm{Aa}$ \\
\hline & \multicolumn{6}{|c|}{45 DAA } \\
\hline Inicial & $2,0 \mathrm{Ca}$ & $15,7 \mathrm{Ba}$ & $18,7 \mathrm{Aa}$ & $0 \mathrm{Ca}$ & $6,5 \mathrm{Ba}$ & $9,5 \mathrm{Ab}$ \\
\hline Tardio & $0 \mathrm{Ca}$ & $4,0 \mathrm{Bb}$ & $9,5 \mathrm{Ab}$ & $0 \mathrm{Ca}$ & $7,7 \mathrm{Ba}$ & $17,0 \mathrm{Aa}$ \\
\hline
\end{tabular}

${ }^{(1)}$ Médias seguidas da mesma letra, minúscula na coluna (época de aplicação dos herbicidas) e maiúscula na linha (herbicidas), dentro de cada cultivar e época de avaliação, não diferem entre si pelo teste $\mathrm{t}(p=0,05)$. 
Tabela 3: População final de plantas, número de grãos por vagem, número de vagens por planta, massa de 100 grãos e produtividade de grãos dos cultivares de feijão-caupi BRS Guariba e BRS Novaera, em função da aplicação de herbicidas nas fases inicial e tardia

\begin{tabular}{|c|c|c|c|c|c|c|}
\hline \multirow{3}{*}{$\begin{array}{l}\text { Época } \\
\text { de aplicação e } \\
\text { testemunhas }\end{array}$} & \multicolumn{3}{|c|}{ BRS Guariba } & \multicolumn{3}{|c|}{ BRS Novaera } \\
\hline & \multicolumn{3}{|c|}{ Herbicida } & \multicolumn{3}{|c|}{ Herbicida } \\
\hline & Bentazona & Fomesafem & Diclosulam & Bentazona & Fomesafem & Diclosulam \\
\hline & \multicolumn{6}{|c|}{ População de plantas (mil plantas ha' ${ }^{-1}$ ) } \\
\hline Inicial & $169,4 \mathrm{Aa}^{(1)}$ & $179,6 \mathrm{Aa}^{*}$ & $125,0 \mathrm{Bb}^{2 \%}$ & $165,7 \mathrm{Aa}$ & $172,2 \mathrm{Aa}$ & $140,7 \mathrm{Bb}^{2 \%}$ \\
\hline Tardio & $168,5 \mathrm{ABa}$ & $179,6 \mathrm{Aa}^{*}$ & $159,2 \mathrm{Ba}$ & $164,8 \mathrm{Aa}$ & $181,5 \mathrm{Aa}^{*}$ & $162,0 \mathrm{Aa}$ \\
\hline $\mathrm{TNC}^{(2)}$ & & 146,3 & & & 149,1 & \\
\hline $\mathrm{TC}^{(3)}$ & & 174,1 & & & 177,8 & \\
\hline \multirow[t]{2}{*}{$\mathrm{d}^{\mathrm{d}^{(4)}}$} & & 23,2 & & & 28,2 & \\
\hline & \multicolumn{6}{|c|}{ № de grãos por vagem } \\
\hline Inicial & $9,2 \mathrm{Aa}$ & $9,4 \mathrm{Aa}$ & $8,4 \mathrm{Aa}$ & $14,3 \mathrm{Aa} *^{2 \%}$ & $7,2 \mathrm{Ca}$ & $11,0 \mathrm{Ba}$ \\
\hline Tardio & $8,1 \mathrm{Aa}$ & $8,3 \mathrm{Aa}$ & $7,9 \mathrm{Aa}$ & $10,6 \mathrm{Ab}$ & $8,6 \mathrm{ABa}$ & $7,9 \mathrm{Bb}$ \\
\hline TNC & & 8,1 & & & 7,8 & \\
\hline $\mathrm{TC}$ & & 8,3 & & & 9,8 & \\
\hline \multirow[t]{2}{*}{ d' } & & 3,4 & & & 3,3 & \\
\hline & \multicolumn{6}{|c|}{ № de vagens por planta } \\
\hline Inicial & $9,1 \mathrm{Aa}$ & $7,4 \mathrm{Aa}$ & 7,5Aa & 2,9Aa & 3,9Aa & $3,9 \mathrm{Aa}$ \\
\hline Tardio & $9,6 \mathrm{Aa}$ & $9,1 \mathrm{Aa}$ & $9,0 \mathrm{Aa}$ & $3,0 \mathrm{Aa}$ & $4,7 \mathrm{Aa}$ & $3,0 \mathrm{Aa}$ \\
\hline TNC & & 7,8 & & & 2,6 & \\
\hline $\mathrm{TC}$ & & 8,7 & & & 5,0 & \\
\hline \multirow[t]{2}{*}{ d' } & & 2,7 & & & 2,7 & \\
\hline & \multicolumn{6}{|c|}{ Massa de 100 grãos (g) } \\
\hline Inicial & $22,6 \mathrm{Aa}$ & $21,5 \mathrm{Aa}$ & $21,5 \mathrm{Ab}$ & $18,2 \mathrm{Ba}$ & $18,5 \mathrm{Ba}$ & $20,0 \mathrm{Aa}^{*}$ \\
\hline Tardio & $23,0 \mathrm{Aa}$ & $23,1 \mathrm{Aa}$ & $23,5 \mathrm{Aa}$ & $18,1 \mathrm{Aa}$ & $18,6 \mathrm{Aa}$ & $18,4 \mathrm{Ab}$ \\
\hline TNC & & 22,5 & & & 17,7 & \\
\hline $\mathrm{TC}$ & & 22,8 & & & 18,8 & \\
\hline \multirow[t]{2}{*}{ d' } & & 2,5 & & & 1,4 & \\
\hline & \multicolumn{6}{|c|}{ Produtividade de grãos $\left(\mathrm{kg} \mathrm{ha}^{-1}\right)$} \\
\hline Inicial & $3.310 \mathrm{Aa}$ & $2.763 \mathrm{ABa}$ & $1.761 \mathrm{Bb}$ & $1.235 \mathrm{Aa}^{*}$ & $927 \mathrm{Bb}$ & $1.197 \mathrm{Ab}^{*}$ \\
\hline Tardio & $3.147 \mathrm{Aa}$ & $3.200 \mathrm{Aa}$ & $2.790 \mathrm{Aa}$ & $928 \mathrm{Bb}$ & $1.381 \mathrm{Aa}^{*}$ & $742 \mathrm{Ba}^{2 \%}$ \\
\hline TNC & & 2.599 & & & 684 & \\
\hline $\mathrm{TC}$ & & 2.528 & & & 1.311 & \\
\hline d' & & 1.492 & & & 438 & \\
\hline
\end{tabular}

este um herbicida registrado para uso na cultura e amplamente empregado no controle em pós-emergência inicial de plantas daninhas latifoliadas. Já Machado et al. (2006) verificaram que a produtividade de grãos do feijão-comum não foi comprometida pela aplicação da mistura dos herbicidas fomesafen e fluazifop-p-butil. Ainda, na Tabela 4, observa-se que a menor produtividade da cultivar BRS Guariba foi proporcionada pela aplicação inicial do diclosulam, enquanto, para a cultivar BRS Novaera, a menor produtividade foi obtida com a aplicação tardia desse mesmo herbicida. Pode-se atribuir esses resultados aos efeitos mais severos de fitotoxicidade causados pelo herbicida diclosulam em ambas as cultivares (Tabela 2).

\section{CONCLUSÕES}

O herbicida diclosulam proporcionou elevada fitotoxicidade e reduziu a população de plantas, enquanto o bentazona proporcionou os menores níveis de fitointoxicação dos duas cultivares de feijão-caupi. O fomesafem, especialmente quando aplicado na fase inicial, foi o mais eficaz no controle das plantas daninhas e, mesmo causando fitotoxicidade à cultura do feijão-caupi, proporcionou população adequada de plantas, bem como produtividades de grãos semelhantes às obtidas com a testemunha capinada, sendo o mais eficiente para as cultivares de feijão-caupi BRS Guariba e BRS Novaera. 


\section{REFERÊNCIAS}

Brasil (2014) Ministério da Agricultura, Pecuária e Abastecimento. Disponível em: <http://agrofit.agricultura.gov.br/ agrofit_cons/ !ap_produto_form_lista_cons>. Acessado em: 20 de março de 2014.

Burgos NR, Brandenberger LP, Stiers EN, Shivrain VK, Motes DR, Wells L, Eaton S, Martin LW \& Morelock TE (2007) Tolerance of selected advanced cowpea (Vigna unguiculata) Breeding Lines to Fomesafen. Weed Technology, 21:863-868.

Castelletti CHM \& Costa AF (2013) Feijão-caupi: alternativa sustentável para os sistemas produtivos. Pesquisa Agropecuária Pernambucana, 18:1-2.

Chikoye D, Abaidoo R \& Fontem LA (2014) Response of weeds and soil microorganisms to imazaquin and pendimenthalin in cowpea and soybean. Crop Protection, 65:168-172.

Corrêa MJP \& Alves PLCA (2009) Eficácia de herbicidas aplicados em pós-emergência na cultura da soja convencional e transgênica. Planta Daninha, 27:1035-1046.

EMBRAPA - Empresa Brasileira de Pesquisa Agropecuária (2006) Sistema brasileiro de classificação dos solos. Brasília, EmbrapaSTI. 412p.

EMBRAPA - Empresa Brasileira de Pesquisa Agropecuária (2002) Cultivo do feijão-caupi - Sistemas de Produção. Disponível em: <http://sistemasdeproducao.cnptia.embrapa.br/FontesHTML/ Feijao/FeijaoCaupi>. Acessado em: 13 de março de 2014.

Fontes JRA, Gonçalves JRP \& Morais RR (2010) Tolerância do feijão-caupi ao herbicida oxadiazon. Pesquisa Agropecuária Tropical, 40:110-115.

Freire Filho FR, Cravo MS, Vilarinho AA, Cavalcante MS, Fernandes JB, Sagrilo E, Ribeiro VQ, Rocha MS, Sittolin IM, Souza FF, Lopes AM, Rocha Neto OG, Celestino Filho P, Gonçalves JRP, Carvalho HWL, Raposo JAA \& Sampaio LS (2008) BRS Novaera: Cultivar de feijão-caupi de porte semi-ereto. Disponível em: <http://www.cpatu.embrapa.br/publicacoes_online/ comunicado-tecnico/2008/brs-novaera-cultivar-de-feijao-caupide-porte-semi-ereto>. Acessado em: 07 de julho de 2015.

Gonçalves JRP, Fontes JRA, Dias MC, Rocha MS \& Freire Filho FR (2009) BRS Guariba - Nova cultivar de feijão-caupi para o estado do Amazonas. Disponível em: < http:// ainfo.cnptia.embrapa.br/digital/bitstream/item/63843/1/ ComTec-76-2009.pdf>. Acessado em: 07 de julho de 2015.

Ishaya VB, Tunkub P \& Yahayac MS (2008) Effect of preemergence herbicide mixtures on cowpea (Vigna unguiculata (L.) Walp) at Samaru, in Northern Nigeria. Crop Protection, 27:1105-1109.

Kissmann KG \& Groth D (1992) Plantas infestantes e nocivas. São Paulo, Basf Brasileira. 798p.

Lamego FP, Basso CJ, Vidal RA, Trezzi MM, Santi AL, Ruchel Q, Kaspary TE \& Gallon M (2011) Seletividade dos herbicidas smetolachlor e alachlor para o feijão-carioca. Planta Daninha, 29:877-883.

Lee HJ, Duke MV \& Duke SO (1993) Cellular localization of protoporphyrinogen-oxidizing activities of etiolated barley (Hordeum vulgare L.) leaves (relationship to mechanism of action of protoporphyrinogen oxidaseinhibiting herbicides). Plant Physiology, 102:881-889.

Li R, Yumei ZG \& Zhanzhi X (2004) Damage loss and control technology of weeds in cowpea field. Weed Science, 2:25-26.

Machado AFL, Camargo APM, Ferreira LR, Sediyama T, Ferreira FA \& Viana RG (2006) Misturas de herbicidas no manejo de plantas daninhas na cultura do feijão. Planta Daninha, 24:107-114.
Muhammad RC, Muhammad J \& Tahira ZM (2003) Yield and yield components of cowpea as affected by various weed control methods under rain fed conditions of Pakistan. International Journal of Agriculture and Biology, 9:120-124.

Oliveira OMS, Silva JF, Gonçalves JRP \& Klehm CS (2010) Período de convivência das plantas daninhas com cultivares de feijão-caupi em várzea no Amazonas. Planta Daninha, 28:523530

Procópio SO, Braz AJBP, Barroso ALL, Cargnelutti Filho A, Cruvinel KL, Betta M, Braz GBP, Fraga Filho JJS \& Cunha Júnior LD (2009) Potencial de uso dos herbicidas chlorimuronethyl, imazethapyr e cloransulam-methyl na cultura do feijão. Planta Daninha, 27:327-336.

Raij B, Andrade JC, Cantarella H \& Quaggio JA (2001) Análise química para avaliação da fertilidade de solos tropicais. Campinas, Instituto Agronômico. 285p.

Sikkema PH, Soltani N, Shropshire C \& Cowan T (2004) Tolerance of white beans to postemergence broadleaf herbicides. Weed Technology, 18:893-901.

Soares ALL, Pereira JPAR, Ferreira PAA, Vale HMM, Lima AS, Andrade MJB \& Moreira FMS (2006) Eficiência agronômica de rizóbios selecionados e diversidade de populações nativas nodulíferas em Perdões, (MG). I-caupi. Revista Brasileira de Ciência do Solo, 30:795-802.

SBCPD - Sociedade Brasileira da Ciência das Plantas Daninhas (1995) Procedimentos para instalação, avaliação e análise de experimentos com herbicidas. Londrina, SBCPD. 42p.

Trezzi MM, Vidal RA, Kleina EA, Thomazi H \& Lamego FP (2010) Paradoxo da dose de herbicidas: comprovação da teoria na cultura do feijão. In: $27^{\circ}$ Congresso Brasileiro da Ciência das Plantas Daninhas, Ribeirão Preto. Anais, SBCPD. p.1635-1639.

Usman I (2013) Effect of pre emergence herbicides on weed control and performance of cowpea in Samaru. The Journal of Agricultural Sciences, 8:76-81.

Xavier GR, Martins LMV, Ribeiro JRA \& Rumjanek NG (2006) Especificidade simbiótica entre rizóbios e acessos de feijãocaupi de diferentes nacionalidades. Revista Caatinga, 19:25-33.

Rev. Ceres, Viçosa, v. 63, n.1, p. 025-032, jan-fev, 2016 